\title{
A STUDY TO ASSESS THE KNOWLEDGE OF STRESS MANAGEMENT TECHNIQUES AMONG PEDIATRIC NURSES IN SELECTED HOSPITALS AT NAGERCOIL
}

\author{
Ms. Prema Latha* \& Dr. Sharmila Jansi Rani** \\ *Ph.D. Scholar, Himalayan University, Itanagar, Arunachal Pradesh, India. \\ **Vice Principal, Christian College of Nursing, Neyyoor, K. K District, Tamilnadu, India. \\ DOI: http://doi.org/10.47211/tg.2020.v07i03.010
}

\begin{abstract}
Stress is a part and parcel of human lifestyle. Stress is a bodily or mental tension resulting from factors that tend to alter an existent equilibrium. Nursing is generally perceived as demanding profession. AIM: The study was carried out with the objectives to assess the knowledge of stress management techniques among pediatric nurses and to associate with their socio demographic variables. METHODS: Non experimental research design was adopted.30 nurses working in selected tertiary care hospital were selected by using convenient sampling technique. TOOL: Data was collected by using self-structured knowledge questionnaire consists of 15 questions regarding Stress management techniques as 2-items of healthy stress comprises 5-questions, and Personal stress comprises 10-questions. RESULTS: Level of knowledge among Age related was more than 30 years were 24(80\%), and less than 30 years were 6(20\%); there is difference in Gender and Marital Status. Regard to Working experience there was no changes in knowledge, but information of Stress management techniques during Last 2 years were very less 20(66.6\%), Attended stress management course during the working period also found very less $7(23.3 \%)$. Thus found there is a poor knowledge regarding Stress management techniques among pediatric nurses. Also there is significant association with level of knowledge on stress management techniques related to age, marital status, gender, information and course attended among pediatric nurses at the level of $p<0.001$. CONCLUSION: The study concludes that majority of the nurses have low knowledge in stress management techniques. It is also found that stress due to work organization and inter personal relationship at work is harder which adds up to the stress. It is evident in the present study that older age group and women were commonly low level of knowledge in stress management techniques. It is recommended to implement strategies for reducing stress, knowledge on stress management techniques and to organize stress management Programme.
\end{abstract}

Key Words: Stress, human lifestyle, nurse, stress management.

\section{ABOUT AUTHORS:}

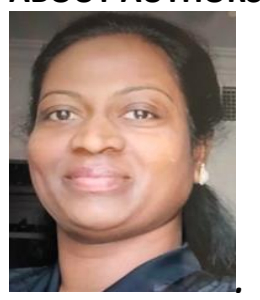

Ms. Prema latha at present working as a Shift manager, Pediatric Neuro Science, National Neuroscience Institute, King Fahad Medical City, Riyadh, Saudi Arabia. She has completed her BSN in the year 1997, MSN in 2007 and also she has additional qualification of BSc (Psy), MSc (Psy) and MPhil (Psy). She has published an article named "Learning disabilities among children, "Study on Achievement motivation of higher students in relation to their noise sensitivity "and "Relationship between percepting behaviors of senior nurses and the performance of Novice nurses "Also she is a PhD scholar in Nursing in Himalayan University.

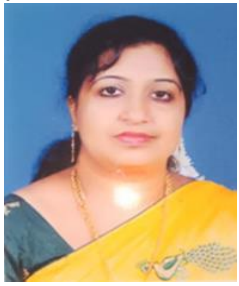

Dr. Sharmila Jansi Rani is a Professor cum Vice Principal, Christian College of Nursing, Neyyoor, K. K District, TamilNadu, India. She has presented papers in various conferences and seminars. She has many research publications in her name. She has attended various National and International conferences, Seminars and workshops 


\section{INTRODUCTION:}

Stress is a feeling of emotional or physical tension. It can come from any event or thought that makes us feel frustrated, angry, or nervous. Stress is our body's reaction to a challenge or demand. In short bursts, stress can be positive, such as when it helps us to avoid danger or meet a deadline. Our body reacts to stress by releasing hormones. These hormones make our brain more alert, cause our muscles to tense, and increase our pulse. In the short term, these reactions are good because they can help you handle the situation causing stress. This is our body's way of protecting itself. (Medical encyclopedia). Aschbacher (2013) Good stress," or what psychologists refer to as "eustress," is the type of stress we feel when we are excited. Our pulse quickens and our hormones surge, but there is no threat or fear. We feel this type of stress when we ride a roller coaster, compete for a promotion, or go on a first date. There are many triggers for this good stress, and it keeps us feeling alive and excited about life. Another type of stress is acute stress. It comes from quick surprises that need a response. Acute stress triggers the body's stress response as well, but the triggers aren't always happy and exciting. This is what we normally think of as "stress" (or "bad stress"). Chronic stress is another form of bad stress. It occurs when we repeatedly face stressors that take a heavy toll and feel inescapable. A stressful job or an unhappy home life can bring chronic stress. This is what we normally think of as serious stress. Because our bodies aren't designed for chronic stress, we can face negative health effects (both physical and emotional) if we experience chronic stress for an extended period of time.

Work-related stress doesn't just disappear when you head home for the day. When stress persists, it can take a toll on your health and well-being. A stressful work environment can contribute to problems such as headache, stomachache, sleep disturbances, short temper and difficulty concentrating. Chronic stress can result in anxiety, insomnia, high blood pressure and a weakened immune system. It can also contribute to health conditions such as depression, obesity and heart disease. Compounding the problem, people who experience excessive stress often deal with it in unhealthy ways such as overeating, eating unhealthy foods, smoking cigarettes or abusing drugs and alcohol. Steward cooper (2012)

Stress management looks at stress as a problem that can be addressed solved, or at least improved, using practical problem-solving methods. It provides a variety of research-backed stress management strategies. It shares real life stories of how people use these specific strategies to manage their stress more effectively. It guides us through a few questions to help us to make use of strategies.

\section{NEED FOR THE STUDY}

Investigator have observed work stress among medical technicians, radiation therapists, social workers, occupational therapists, physicians, and collections of health care staff across disciplines but most of the problem focused on nurses. Numerous recent studies have explored work stress among health care personnel in many countries mainly in the nursing profession. It is looking at threats as challenges more often; it becomes more automatic, and experience more good stress and less bad stress. Findings are also emerging about differences in work stress based on shift length and generational cohort. The investigator wants to assess the relation between stress and its factors like family-work conflict, Nurses working 12-hour shifts, Personal stress to work, Verbal abuse from physicians or with Nurses in supervisory positions.

Despite lacking absolute clarity, there is a body of research addressing work stress that spans more than 50 years in the nursing profession. Stress is pervasive in nursing and health care. Moreover, working conditions seem to be deteriorating at the same time that a severe and protracted nursing shortage is occurring. Leaders of health care organizations can no longer ignore these findings. So the investigator recommended a need to further study to reduce the stress by some useful stress techniques.

\section{STATEMENT OF THE PROBLEM}

"A Study to assess the knowledge of Stress management techniques among pediatric nurses in selected Hospitals at Nagercoil"

\section{OBJECTIVES}

1. To assess the knowledge of Stress management techniques among pediatric nurses

2. To find out the association between the knowledge of Pediatric nurses regarding Stress management techniques and the selected socio-demographic variables.

3. To develop and validate an information booklet regarding Stress techniques 


\section{LITERATURE REVIEW:}

A literature review is a comprehensive summary of previous research on a topic. The literature review surveys scholarly articles, books, and other sources relevant to a particular area of research. The review should enumerate, describe, summarize, objectively evaluate and clarify this previous research

In the cross-sectional study of 189 nurses from Kashan hospitals revealed job stress aspects and the results showed that the level of stress in most of the nurses was in medium level. Job factors were more involved in job stress than demographic and other factors. Arash Najimi (2012). The study by Rebekah K. Hersch (2016) as randomized controlled trial was conducted with 104 nurses in five hospitals in Virginia and one hospital in New York to evaluate the effectiveness of the web-based Breath: stress management for nurse's program. Program group participants experienced significantly greater reductions than the control group on the full Nursing Stress Scale, and six of the seven subscales.

\section{RESEARCH METHODOLOGY}

Research approach: Quantitative approach.

Research design: Non experimental design

Setting of the study: The study was conducted in Nagercoil

Population: All the pediatric nurses in the selected hospitals during the period of data collection constituted the population of the study.

\section{SAMPLE AND SAMPLING TECHNIQUE}

Sample: The Pediatric nurses are the sample for this study.

Sample Size: Sample size is 30

Sample Technique: Convenient sampling

Sample Selection Criteria:

The sample was selected based on the following: Inclusion criteria as Pediatric nurses in all units in the selected hospitals and Pediatric nurses who are willing to participate in the study; Exclusion criteria as All other nurses in the unit except pediatric nurses, those pediatric nurses who are not willing to participate in the study, Pediatric nurses who were taken for Pilot study group

Material and Methods: Based on objectives, Review of literature and Need for the Study the study utilized SelfStructured questionnaire of stress management techniques which had 15 items. The received questionnaire was then screened for the suitability of responses to get the final number of participants.

Research Tool: The demographic variables as mentioned were coded to assess the background of the pediatric nurses. And Self-Structured Knowledge questionnaire consists of 15 items related to Stress management knowledge questions and the possible answer was "YES" or "NO"

Validation of Tool: The tool validation given to the Nursing Experts, Medical experts, Psychologists and Pediatricians

Tool Reliability: The reliability of the tool was calculated using Inter consistence method (Cron Bach's Alpha) and reported as 0.93

Protection of human Rights: The study was selected after the research selection committee. And written permission was obtained from the hospital authority. Once the approval obtained the study was conducted upon the interest and participation of the subjects.

Data Collection: Before data were collected the researcher visited the hospitals to coordinate and formulate plans for data. The nurses were approached after the endorsement. The nurses were provided adequate information about the study. After signing the informed consent Confidentiality were obtained. The nurses were handed the questionnaire and given 15 minutes to complete. After the allotted time the researcher collected the Questions.

Data Analysis: The obtained objectives and hypothesis was analyzed by using descriptive and inferential statistics. 


\section{ARTICLES}

Table: 1 Sample characteristics of pediatric nurses $\mathrm{N}=\mathbf{3 0}$

\begin{tabular}{|c|c|c|c|c|}
\hline SL:NO & \multicolumn{2}{|l|}{ VARIABLES } & $\mathbf{n}$ & $\%$ \\
\hline \multirow[t]{2}{*}{1} & \multirow[t]{2}{*}{ Age } & $<30$ yrs. & 6 & 20 \\
\hline & & $>30$ yrs. & 24 & 80 \\
\hline \multirow[t]{2}{*}{2} & \multirow[t]{2}{*}{ Gender } & Female & 26 & 86.6 \\
\hline & & Male & 4 & 13.3 \\
\hline \multirow[t]{2}{*}{3} & \multirow[t]{2}{*}{ Marital Status } & Single & 7 & 23.3 \\
\hline & & Married & 23 & 76.6 \\
\hline \multirow[t]{2}{*}{4} & \multirow[t]{2}{*}{ Working experience in Nursing Profession } & $0-10$ yrs. & 15 & 50 \\
\hline & & $>10$ yrs. & 15 & 50 \\
\hline \multirow[t]{2}{*}{5} & \multirow[t]{2}{*}{ Information of Stress management techniques during Last 2 years } & Yes & 10 & 33.3 \\
\hline & & No & 20 & 66.6 \\
\hline \multirow[t]{2}{*}{6} & \multirow[t]{2}{*}{ Attended stress management course during the working period } & Yes & 7 & 23.3 \\
\hline & & No & 23 & 76.6 \\
\hline
\end{tabular}

Level of knowledge among Age related was more than 30 yrs. were 24(80\%), and less than 30 yrs. were $6(20 \%)$; there is difference in Gender and Marital Status. Regard to Working experience was no changes in knowledge, but information during last 2 years were very less 20(66.6\%), Regarding Attended course during the working period also found very less $7(23.3 \%)$. Thus found there is a poor knowledge regarding Stress management techniques among pediatric nurses.

Table: 2: Association between participant demographic characteristics and Stress management techniques among pediatric nurses

\begin{tabular}{|c|c|c|c|c|c|c|}
\hline SL:NO & VARIABLES & & $M$ & S.D & t-value & \\
\hline \multirow[t]{2}{*}{1} & \multirow[t]{2}{*}{ Age } & $<30$ yrs. & 6.17 & 2.77 & \multirow[t]{2}{*}{-5.62} & \multirow[t]{2}{*}{$<0.001$} \\
\hline & & $>30$ yrs. & 4.46 & 3.39 & & \\
\hline \multirow[t]{2}{*}{2} & \multirow[t]{2}{*}{ Gender } & Female & 5.30 & 3.24 & \multirow[t]{2}{*}{4.63} & \multirow[t]{2}{*}{$<0.001$} \\
\hline & & Male & 5.07 & 3.35 & & \\
\hline \multirow[t]{2}{*}{3} & \multirow[t]{2}{*}{ Marital Status } & Single & 4.30 & 3.10 & \multirow[t]{2}{*}{-5.06} & \multirow[t]{2}{*}{$<0.001$} \\
\hline & & Married & 5.90 & 3.18 & & \\
\hline \multirow[t]{2}{*}{5} & \multirow{2}{*}{$\begin{array}{l}\text { Information of Stress management techniques } \\
\text { during Last } 2 \text { years }\end{array}$} & Yes & 4.38 & 3.12 & \multirow[t]{2}{*}{-5.10} & \multirow[t]{2}{*}{$<0.001$} \\
\hline & & No & 5.98 & 3.20 & & \\
\hline \multirow[t]{2}{*}{6} & \multirow{2}{*}{$\begin{array}{l}\text { Attended stress management course during the } \\
\text { working period }\end{array}$} & Yes & 4.64 & 3.02 & \multirow[t]{2}{*}{-5.23} & \multirow[t]{2}{*}{$<0.001$} \\
\hline & & No & 6.35 & 3.37 & & \\
\hline
\end{tabular}

There is significantly associated with level of knowledge on stress management techniques related to age, marital status, information and course attended among pediatric nurses. 


\section{SUMMARY}

Stress and burnout are concepts that have sustained the interest of nurses and researchers for several decades. These concepts are highly relevant to the workforce in general and nursing in particular. Despite this interest and relevance, the effects of stress and burnout on patient outcomes, patient safety, and quality care are not well defined by evidence. In fact, the link between stress and burnout to patient outcomes has been explored in the investigations. There is a great need for comprehensive studies that will examine these dynamics in a way that will yield more solid evidence on which to base practice.

\section{CONCLUSION}

The study provides significant information on the stress management techniques of pediatric nurses in Nagercoil. The level of knowledge is significantly lower than the level reported in previous studies of this issue around the world.

\section{LIMITATIONS:}

The study was conducted only in 2 hospitals, the use of convenience sampling may affect the generalizes of findings, the type of educational training programs that the pediatric nurses attended were not thoroughly elucidated in the study.

\section{IMPLICATIONS:}

The findings may be used as a basis for establishing educational policies and interventions to enhance stress management among pediatric nurses, Additional learning opportunities such as stress management techniques should be provided to all nurses to strengthen their knowledge, Stress management seminar and training can be provided at least twice a year for nurses to reinforce their knowledge.

\section{REFERENCES:}

1. Medical Encyclopaedia (2018), department of Health and Human Services, National Institute of Health, Rock ville, Pike Publications.

2. Aschbacher etal (2013) Good stress, Bad Stress, Oxidative Stress, Psycho Endocrinology $8^{\text {th }}$ Edition, pp:708-1698

3. Gray-Toft and T.G. Anderson (1981) "The nursing stress scale: Development of an instrument", International Journal of Behavioral Assessment, 3, 11-23

4. Pearlin LI. (1983) Role strains and personal stress. In: Kaplan HB, editor. Psychological stress Trends in theory and research. New York: Academic Press; pp. 3-32.

5. Maslach C, Jackson S. Burnout in health professions (1982): A social psychological analysis. In: Sanders G, Suls J, editors. Social psychology of health and illness. Hillsdale, NJ: Lawrence Erlbaum; pp. 79-103.

6. Arash Najimi (2012) Causes of job stress in nurses: Iranian Journal of Nursing and Midwife Research, $17^{\text {th }}$ Publication, (4), May-June (2012), pp:301-305

7. Stewart Coooper (2012) Consulting Psychology Journal: Practice and Research, Vol. 64, December, No.4, pp:8-12

8. Rebekah k. Hersch (2016) Reducing nurses' stress: A randomized controlled trial of a web-based stress management program for nurses, November, Pp. 18-25

\section{BOOKS}

1. Adam T. C., Empel E. S. Stress eating and the reward system. Physiology \& Behavior, 2007; 91, 449458.

2. Selye H. (1956) the stress of life. New York: McGraw Hill Publications; 1956, PP:34-41

3. Gray-Toft and T.G. Anderson. (1981). "Stress among hospital nursing staff: Its causes and effects", Social Science and Medicine, 15A, 539-647.

4. Greeson J.M. Mindfulness Research Update: 2008. Complement Health Pract Rev, 2009; 14(1), 10-18.

5. Hill house JJ, Adler CM. (1997). Investigating stress effect patterns in hospital staff nurses: Results of a cluster analysis. Social Science Medicine, 45, 1781-1788

6. Pelletier KR. (1984) Healthy people in unhealthy places. New York: Delacorte Press; PP:78-99

7. Titlebaum H. M. Relaxation. Holistic Nursing Practice, 1998; 2(3), 17-25.

\section{NET REFERENCE:}

8. https://www.euro.who.int/_data/assets/pdf_file/0008/96452/E87301.pdf. 